IZA DP No. 8820

Compensating Differentials in Experimental Labor Markets

Jeffrey Carpenter

Peter Hans Matthews

Andrea Robbett

January 2015 


\title{
Compensating Differentials in Experimental Labor Markets
}

\author{
Jeffrey Carpenter \\ Middlebury College \\ and IZA
}

Peter Hans Matthews

Middlebury College

Andrea Robbett

Middlebury College

\section{Discussion Paper No. 8820 \\ January 2015}

IZA
P.O. Box 7240
53072 Bonn
Germany

Phone: +49-228-3894-0

Fax: +49-228-3894-180

E-mail: iza@iza.org

Any opinions expressed here are those of the author(s) and not those of IZA. Research published in this series may include views on policy, but the institute itself takes no institutional policy positions. The IZA research network is committed to the IZA Guiding Principles of Research Integrity.

The Institute for the Study of Labor (IZA) in Bonn is a local and virtual international research center and a place of communication between science, politics and business. IZA is an independent nonprofit organization supported by Deutsche Post Foundation. The center is associated with the University of Bonn and offers a stimulating research environment through its international network, workshops and conferences, data service, project support, research visits and doctoral program. IZA engages in (i) original and internationally competitive research in all fields of labor economics, (ii) development of policy concepts, and (iii) dissemination of research results and concepts to the interested public.

IZA Discussion Papers often represent preliminary work and are circulated to encourage discussion. Citation of such a paper should account for its provisional character. A revised version may be available directly from the author. 


\section{ABSTRACT}

\section{Compensating Differentials in Experimental Labor Markets}

The theory of compensating differentials has proven difficult to test with observational data: the consequences of selection, unobserved firm and worker characteristics, and the broader macroeconomic environment complicate most analyses. Instead, we construct experimental, real-effort labor markets and offer an evaluation of the theory in a controlled setting. We study both the wage differentials that evolve between firms with varying degrees of disamenity and how these differentials are affected by worker mobility and therefore selection. Consistent with the theory, we find that riskier firms must pay significantly higher wages to attract workers. Further, when workers are mobile, they sort into firms according to their attitudes towards risk and, as a result, the compensating differential shrinks. Last, we are also able to mimic the biases associated with observational studies.

JEL Classification: J31, D01, C92

Keywords: compensating differential, sorting, experiment, real effort, risk aversion, ambiguity aversion, loss aversion

Corresponding author:

Jeffrey Carpenter

Department of Economics

Middlebury College

Middlebury, VT 05753

USA

E-mail: jpc@middlebury.edu 
The whole of the advantages and disadvantages of the different employments of labour and stock must, in the same neighborhood, be either perfectly equal or continually tending to equality. (Smith, 1976 [1776], Book I, ch. X, p. 111)

\section{Introduction}

It is difficult to believe that almost two and a half centuries after Smith (1776) first described the basic logic behind compensating differentials, considerable doubt remains about the size, and sometimes even the existence, of differentials for even the most salient of disamenities, including death. Using panel data, for example, Kniesner et al. (2012) report estimates of the value of a statistical life between $\$ 6$ and $\$ 26$ million, in which the confidence interval for the former includes zero! Worse, perhaps, Dorman and Hagstrom (1998) find that for non-union workers, the mean differential is in fact negative.

In principle, calculation of an equalizing difference, the compensation needed to make

the marginal worker indifferent between positions with and without disamenities, should be straightforward. In practice, however, credible estimates have proven elusive, for at least two sorts of reasons. The first reflect the limitations of observational datasets. Data at both the firm- and job-level is often scarce, for example, which means that important distinctions are either unobserved or measured at inappropriate levels of aggregation. It is often the case, for example, that disamenities are measured at the sectoral, and not firm, level, which can cause researchers to overestimate differentials (Dorman and Hagstrom 1998). More often than not, researchers also lack sufficient individual-level data to control for firm- and sector-level selection, which makes it difficult, if not impossible, to determine whether, for example, a small differential is the result of "market failure" or otherwise productive selection (Goddeeris 1998; Garen 1988; Kostiuk 1990; Hwang et al. 1992; Lavetti 2014).

The second set of reasons is rooted in various labor market complications, and would muddle estimation even with more complete datasets. For example, the standard rationale for the emergence of compensating differentials presumes vigorous and well-informed job search in a world where labor market frictions and incomplete information are omnipresent (Hwang et al., 1998; Bonhomme and Jolivet, 2009). Absent evidence on motivation, it can also be 
difficult to distinguish between voluntary and involuntary job changes (Taber and Vejlin 2011). Furthermore, if work at firms with disamenities is also harder to observe, or write contracts on, wage differentials will also include a rent (Ho 2013). Macroeconomic conditions - in particular, the jobless rate - can also influence firm-level differentials (Dorman 1998).

None of this has stopped labor economists from attempting to measure, and evaluate, compensating differentials in the field. There are, for example, dozens, if not hundreds, of papers on compensation for health risks, from the existence of a wage premium for oil workers at sea and on the permafrost, military bonuses for combat troops, or even higher rates for sex workers who do not insist on condom use (Rao et al., 2003). There are likewise numerous studies of income risk. In some cases, the risk assumes the form of a small likelihood of a large payoff, as in the arts, sports or entertainment (Hartog and Vijverberg, 2007). In other cases, the income risk comes from an increased likelihood of job loss, including the chance that accidents can lead to long unemployment spells (Hamermesh and Wolfe, 1990).

Our paper makes two substantial contributions to the literature. First and foremost, we are, to our knowledge, the first to use experimental labor markets to construct "clean" estimates of compensating differentials in the face of well-defined risks, both with and without sorting. Second, because our data also allow us to mimic what a researcher with incomplete observational data would see, we can reproduce, but also understand better, the biases embodied in conventional estimates, a novel application of experimental methods.

To be more precise, we construct experimental labor markets that allow us to control the basic determinants of wages - the production process, output prices, labor demand - as we introduce cross-firm variation in the riskiness of compensation, a design consistent with the presence of either income and/or employment risk. Because there are no other differences in the managerial decision problem, whatever wage differentials arise should reflect their response to the revealed preferences of workers for the disamenity. Furthermore, because the "workers" are experimental participants, we are also able to generate measures of each worker's risk preferences.

To evaluate the effects of selection, we include two mobility treatments. In one treatment, it is expensive for workers to migrate from one firm to another, and few do, and the resulting wage difference can be understood as the "full" or "pre-sorting" differential. In the second, high 
mobility, treatment, it is much cheaper for workers to migrate, which allows us to evaluate how much the matching of workers and firms, the basis for the hedonic wage function that Rosen (1986) called the "fundamental (long-run) market equilibrium construct in labor economics," reduces the full differential, a result with important theoretical and empirical implications.

Our experimental design is unique. ${ }^{1}$ Firm managers compete on piece rates to attract workers to their firms, where they exert real effort. The firms are identical, except that in one firm we introduce a disamenity: in each period, there is a $25 \%$ chance that a worker's effort, and thus earnings, will be lost. To measure worker tolerance for the disamenity, we collect incentivized risk attitudes from all of our participants, including measures of ambiguity and loss aversion. Workers are randomly assigned to the catchment area of one of the two firms, but can commute to the other firm at a cost. By varying the commuting cost, we control the extent to which endogenous sorting can occur, and thus can measure the effect of sorting on the differential. The design allows us to avoid the two main challenges described above: first, we can study the evolution of compensating differentials in the absence of competing labor market complications; and, second, we can directly observe both firm characteristics (which we control) and worker characteristics (which we measure).

In this setting, we find considerable support for the Smithian model. In almost all sessions, a significant differential, in both substantive and statistical senses, soon emerged and then persists. If the marginal worker is not risk loving, however, the difference isn't sufficient to compensate workers for their assignment to the risky firm. In this sense, even in our "stripped down" environment, markets fail. We also find, however, that the differential shrinks when workers are mobile and, consistent with the basic theoretical model, that workers sort on the basis of their risk preferences. In our data, the effects of selection, or worker-firm matching, are equivalent to between one quarter and one third of the "full differential."

Last, we show that a researcher who had access to all of our data except for worker characteristics, a common deficit, would underestimate the differential almost $25 \%$, while a researcher forced to use sectoral, rather than firm, characteristics would vastly overestimate it.

\footnotetext{
${ }^{1}$ The closest experiments to ours are Fehr, Gächter and Kirchsteiger (1996) and Fehr, Kirchsteiger and Riedl (1996) in that these authors are also interested in wage setting dynamics, but the focus of these papers (on gift exchange and the evolution of non-compensating differentials) is very different.
} 


\section{Experimental Design}

\subsection{Labor Market Set-up}

Participants were recruited from the undergraduate student body at Middlebury College. The students arrived to the lab in groups of 18 or 24 participants at a time and were assigned to "labor markets" of six participants each. Within each labor market, there were two firms: the Safe (Red) Firm and the Risky (Blue) Firm. ${ }^{2}$ Two of the six participants were assigned to be managers and the remaining four participants were workers. Each manager was tied to a single firm but workers could move between firms. These roles were fixed for the duration of the experiment, which lasted 15 periods.

The manager's job was to set the piece rate in his firm and he could choose any integer between 1 and 100 experimental points. To simplify the tâtonnement process of wage setting, the managers made this choice sequentially at the start of every period. In each period, it was randomly determined whether the Safe Firm manager or the Risky Firm manager went first. The workers then viewed the piece rates at both firms and chose which firm to join for the period. Workers were always free to chose a different firm in the following period. Workers also had an outside option: rather than choosing to work at one of the two firms they could choose the "Orange Option," self-employment, which paid a piece rate of 40 points. This set a floor, below which wages should not fall.

The workers then completed a real effort task. They had one minute to solve addition problems and their earnings were determined by their output and the piece rate either set by the manager of their firm or the one linked to self-employment. Solving addition problems is a common task in the related literature (e.g., Sutter and Weck-Hannemann, 2003 or Niederle et al., 2013) and our workers could produce as many "sums" from three two-digit numbers as possible during the minute. For each unit of output produced by a worker in his firm, the manager earned 100 points minus the piece rate.

To incentivize participants to treat each period separately (à la Hey and Lee, 2005), they were paid according to their earnings from one randomly selected period plus their earnings

\footnotetext{
${ }^{2}$ In the instructions and throughout the experiment, the Safe Firm was referred to as the "Red Firm" and the Risky Firm as the "Blue Firm" to avoid priming our participants. For the sake of clarity, we use the more descriptive names in the paper. A full set of instructions can be found in the appendix.
} 
from one randomly chosen decision from a risk preference elicitation task described below. These earnings were converted to US dollars at the rate of 25 points $=1$ USD and added to a $\$ 5$ show-up fee.

\subsection{Differences Between Firms and Mobility}

In the Safe Firm, workers' earnings for the period were equal to the piece rate times the number of problems correctly solved. In the Risky Firm, however, this was true only with probability 0.75. With probability 0.25 , the worker's output would be lost and he would not be paid for the period's work. This was determined by a different random draw for each worker in the Risky Firm in the period. The risk that the workers in the Risky Firm faced was common knowledge among all participants. The manager of the Risky Firm was always paid according to the worker's output, even if the worker was not, so that the Risky Firm manager faced no additional risk. All else equal, we expected that the resulting disamenity would cause all workers to prefer the Safe Firm, providing the conditions for a standard compensating differential to evolve to compensate Risky Firm workers for their expected loss.

To address the question of whether selection leads to smaller compensating differentials, we varied the mobility of the workers by introducing commuting costs. Specifically, the participants were told that two of the four workers in the labor market lived near the Safe Firm and two lived near the Risky Firm. In order to work at a firm outside one's home zone, the worker must pay a fixed commuting cost for that period. There was no cost associated with working at the firm within one's home zone or with choosing self-employment. We conducted two treatments: one with a low commuting cost of 10 points per period (Low Cost) and one with a much larger commuting cost of 100 points per period (High Cost). ${ }^{3}$ The commuting cost was subtracted from the worker's earnings for the period. A worker who commuted to the Risky Firm and then lost all earnings for the period would receive a negative payoff, which was subtracted from the show-up fee.

This set-up leads to several clear predictions. First, imagine the extreme case in which

\footnotetext{
${ }^{3}$ These parameter values were set after observing participant behavior in a pilot experiment. On average, participants solve between 5 and 6 addition problems each period and they are paid a piece rate greater than 40 (the piece rate of the outside option) for each. Thus paying a commuting cost of 10 has a negligible impact on earnings, while a cost of 100 is substantial.
} 
commuting costs are high enough that no one ever works outside their home zone. In this case, the Safe Firm manager would simply need to pay a piece rate greater than the outside option of 40 points. The Risky Firm manager, however, would need to pay a piece rate much higher than 40 for workers to be willing to bear the risk. Thus, in the High Cost treatment, we expect to see low mobility and significantly higher piece rates offered in the Risky Firm than in the Safe Firm.

In the Low Cost treatment, the most disamenity-averse workers should flock to the Safe Firm. The disamenity-tolerant workers, however, may choose the Risky Firm, but they should require a smaller differential to do so. Thus, in the Low Cost treatment, we expect sorting according to worker risk preferences which should result in a smaller wage differential than in the High Cost treatment.

\subsection{Risk Tolerance Elicitation}

Prior to participating in the main experiment, participants made three lottery choice decisions constructed to elicit their tolerance for the risky disamenity. In each, participants were presented with six lotteries, as shown in the three panels of Figure 1, and asked to choose one. At the end of the experiment, so that the outcomes could not affect labor market behavior, one of three decisions was randomly selected and the chosen lottery was implemented. The three decisions are borrowed from a large-scale field study by Carpenter and Cardenas (2013).

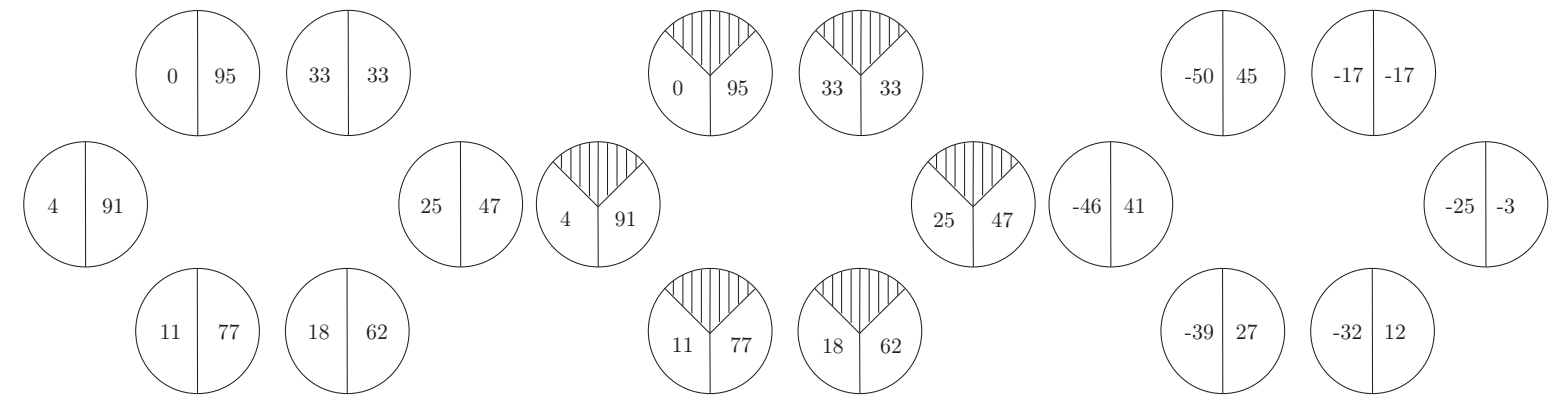

Figure 1: Three Lottery Decisions

The first decision, shown in the leftmost panel, was a simple risk preference elicitation. Participants were told to think of each lottery as a bag, containing five high-value balls and five low-value balls. One ball would be drawn from the bag of their choice and they would be paid 
accordingly. For each decision, the lotteries were numbered clockwise from 1 to 6 . Individuals with preferences close to risk neutrality are expected to choose lottery 5 , which has the highest expected value (i.e., a coin toss resulting in payoffs of either 4 or 91 ). Moving from lottery 5 to lottery 6 , the expected value decreases and the variance increases, indicating that lottery 6 would be chosen only by risk-seekers. Among the other four lotteries, lower lottery choices indicate greater risk aversion.

The second decision, shown in the middle panel, preserves the same numbers on the high and low value balls in each of the lotteries, but introduces ambiguity in the probability of each being chosen. Rather than knowing that there are 5 high-value and 5 low-value balls in each bag, subjects are told that there are at least 2 high-value balls, at least 2 low-value balls, and that the values of the remaining six balls may be high or low. Following Carpenter and Cardenas (2013) (and implicitly Ellsberg, 1961), we define ambiguity aversion as the difference between the lottery chosen in the left (risky) panel and the lottery chosen in middle (ambiguous) panel: Ambiguity Aversion = Risk Choice Lottery Number - Ambiguity Choice Lottery Number. In other words, someone who chooses a lower, safer lottery number in the presence of ambiguity is said to exhibit positive ambiguity aversion.

In the final decision, shown in rightmost panel, subjects are first told that they have been given 50 points to start and that they, again, must pick one of the six lotteries. In this case, the only difference between the leftmost choice and the rightmost choice is framing. The lotteries on the right are identical to those on the left, only the 50 point endowment has been subtracted from each value. Again following Carpenter and Cardenas (2013), loss aversion is defined as the difference between the lottery chosen on the right and the lottery chosen on the left: Loss Aversion $=$ Loss Choice Number - Risk Choice Number. Loss aversion is thus positive if a subject moves to a higher, riskier lottery choice to avoid certain losses.

\section{Results}

\subsection{Description of Data}

We conducted seven "labor markets" of the Low Cost treatment and eight of the High Cost treatment. Overall, 90 students participated in the experiment. Participants earned $\$ 15.64$ 
on average plus a $\$ 5$ show-up fee, with earnings ranging between $\$ 0.16$ and $\$ 39$. Summary statistics for each treatment are provided in Table 1.

\begin{tabular}{lccccc}
\multicolumn{7}{c}{ Table 1: Summary Statistics } \\
\hline \hline & High Cost & Low Cost & Min & Max & p-value \\
\hline Risk Choice & 2.98 & 2.91 & 1 & 6 & .821 \\
Ambiguity Choice & $(1.64)$ & $(1.45)$ & & & \\
& 2.94 & 2.64 & 1 & 6 & .413 \\
Loss Choice & $(1.54)$ & $(1.86)$ & & & \\
& 3.88 & 3.48 & 1 & 6 & .175 \\
Ambiguity Aversion & $(1.38)$ & $(1.38)$ & & & \\
& .04 & .26 & -5 & 5 & .598 \\
Loss Aversion & $(2.13)$ & $(1.77)$ & & & \\
\multirow{5}{*}{ Commuting } & .9 & .57 & -3 & 4 & .305 \\
& $(1.45)$ & $(1.53)$ & & & \\
& .16 & .43 & & & .000 \\
\hline \hline
\end{tabular}

Standard deviations in parentheses

We first look at the risk attitudes elicited with the three lottery choices. The first three rows of Table 1 show the average lottery number chosen in each of the three decisions by participants in the High Cost treatment and the Low Cost treatment. There is substantial variation in the choices made by the participants, with each of the eighteen available lotteries being chosen by at least a few individuals. We find no significant difference in any of the three lottery choices between the Low Cost treatment and the High Cost treatment. The next two rows show the average Ambiguity Aversion and Loss Aversion in each treatment. Across both treatments, there was considerable variation in both Loss and Ambiguity aversion and, on average, participants exhibited positive Loss Aversion $(p<0.01)$ and positive but insignificant Ambiguity Aversion $(p=0.49)$. Again, there is no difference between the two treatments. Additionally, there is no significant difference in the three lottery choices, Ambiguity Aversion, or Loss Aversion exhibited by workers assigned to the Safe Firm zone compared with those in the Risky Firm zone ( $p$-values all greater than 0.5$)$. Thus it appears that the random assignment both into treatments and into zones was successful.

The final row shows the frequency with which workers commute to work outside of their home zones. While workers in the High Cost treatment commute in sixteen percent of opportunities, workers in the Low Cost treatment commute in forty-three percent of opportunities. 
This indicates that the commuting cost treatments had the intended impact on worker mobility.

\subsection{Do Differentials Evolve to Compensate Workers for the Risky Disamenity?}

We first look at whether there is evidence of compensating differentials evolving between our two firms. The two panels in Figure 2 show the piece rates over time in the two treatments. In each, the solid line shows the log piece rate in the Safe Firm and the dashed line shows the log piece rate in the Risky Firm. In both the High and Low Cost treatments, we observe a stable, significant differential in the piece rates offered between the two firms. The difference between piece rates is significant at all reasonable levels in both treatments. ${ }^{4}$ Our results thus strongly support the prediction that differentials will evolve to compensate workers who are exposed to greater risk.

The gray bars in Figure 2 show the number of workers in the Safe Firm in the period. In most periods (over 80 percent of observations), the two firms split the workforce, rather than one firm employing all four workers. In the Low Cost treatment, the Safe Firm attracts 2.7 workers on average. In the High Cost treatment, workers commute less frequently and the average number of workers in the Safe Firm is closer to 2. However, the differential that evolves does not quite compensate for the possibility of losing one's earnings in the Risky Firm. Considering gross earnings (the piece rate times the observed effort) we do find, as the differential suggests, that Risky Firm workers earn more on average $(p=0.03)$ but when we account for the realized $24 \%$ of workers who lost their earnings, mean earnings flip and Risky Firm workers earn less $(p<0.01)$. Despite the differential, our Risky Firm managers do not fully compensate for the disamenity.

\subsection{Are Differentials Influenced by Worker Mobility?}

We next examine whether the ability of workers to select their firm leads to smaller differentials. A comparison between the panels of Figure 2 suggests that the differential is in fact smaller in the left panel, in which costs are lower and workers are therefore more mobile. This result is confirmed in Table 2. The first column of Table 2 presents the estimates of an OLS regression

\footnotetext{
${ }^{4}$ Even treating each labor market as a single observation (i.e., averaging across periods), the difference remains significant at the $p=0.002$ level in both the High Cost and Low Cost treatments.
} 

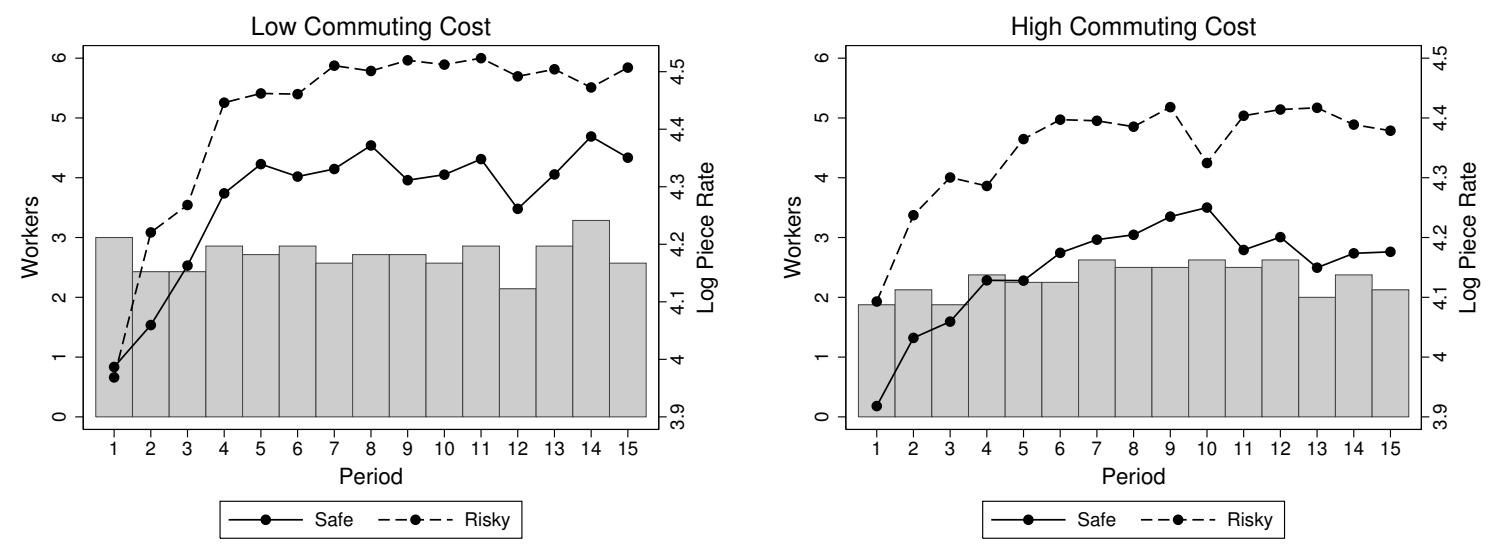

Figure 2: Piece Rates and Safe Firm Employment Over Time

model in which the differential is regressed on a dummy for whether costs are low. We see that the differential is significantly smaller $(5.25 \%$, to be precise) in the Low Cost sessions ( $p=$ 0.013). The additional columns add robustness checks to the model by clustering the standard errors at the session level (Column 2) and including session-level random effects (Column 3). Given the standard errors and point estimates change little, we find that the basic result - the differential shrinks significantly when workers can sort - is robust.

Table 2: Compensating Differential (By Commuting Cost)

\begin{tabular}{lcccc}
\hline \hline & $(1)$ & $(2)$ & $(3)$ & $(4)$ \\
& OLS & OLS & Cluster Session & Random Effects \\
\hline Low Cost Treatment & & $-0.053^{* *}$ & $-0.053^{*}$ & $-0.053^{* *}$ \\
& & $(0.021)$ & $(0.019)$ & $(0.023)$ \\
Constant & & & & \\
& $0.175^{* * *}$ & $0.200^{* * *}$ & $0.200^{* * *}$ & $0.200^{* * *}$ \\
\hline Observations & $(0.011)$ & $(0.016)$ & $(0.013)$ & $(0.016)$ \\
\hline \hline
\end{tabular}

Dependent variable is the log differential. (Robust standard errors).

${ }^{*} p<0.10,{ }^{* *} p<0.05,{ }^{* * *} p<0.01$

\subsection{Do Workers Sort Based on Their Tolerance for the Disamenity?}

Finding that the wage gap associated with the risky disamenity shrinks when workers are mobile is consistent with the standard theory of compensating wage differentials. However, it does not confirm the hypothesized mechanism: the differential shrinks because workers select into firms according to their risk preferences. To examine whether the hypothesized mechanism is correct, 
we first look at whether the commuting costs themselves are influencing worker movement into firms in the way that we predicted; we then turn to whether firm selection is driven by the elicited worker preferences.

Figure 3 shows the relative frequency with which workers in the two zones select into each firm. On the left side, we see that workers in the High Cost treatment typically choose their home firm. This is particularly true of workers in the Safe Firm zone, who choose the Safe Firm over 90 percent of the time and never choose the outside option, suggesting that the Safe Firm bosses understand that they need to pay a piece rate above 40 . Workers who live in the Risky Firm zone occasionally choose the outside option or to commute. In the Low Cost treatment, in contrast, there is much less bias toward choosing one's home firm and the outside option is essentially never taken. Overall, only $16 \%$ of workers "commute" in the High Cost treatment while almost three times as many (43\%) do when the cost of commuting is low $(p<0.01)$. It thus appears that the cost treatments worked as intended.

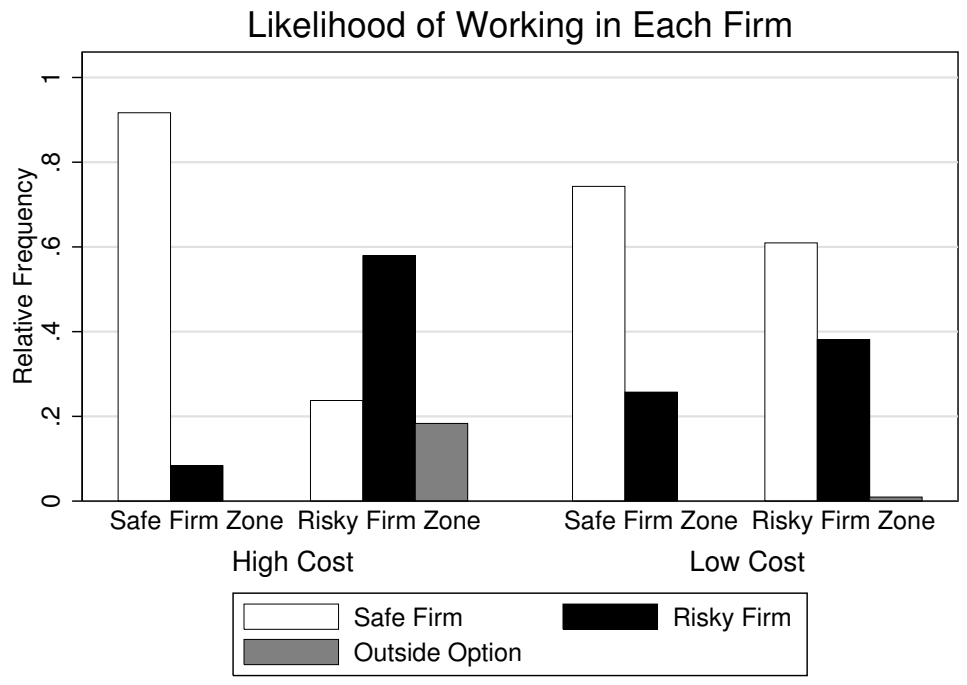

Figure 3: Relative Frequency of Joining Firm

More crucially, we ask whether workers sort into firms on the basis of their risk attitudes, and whether this selection is muted when commuting costs are high. To begin, workers who are unwilling to take risks in our instrument do show a slight preference for the Safe Firm; however, the preference is not strong enough to generate a significant result. This result echoes the finding of Carpenter and Cardenas (2013) that the lottery chosen in the Risk Choice task 
is not strongly predictive of outcomes, and so we, like them, refocus our attention on the two variables derived from the participants' lottery choices: Ambiguity Aversion and Loss Aversion.

The left panel of Figure 4 shows the average level of Ambiguity Aversion in each of the two firms by treatment. When the cost of commuting is high, the Safe Firm workers tend to be slightly more ambiguity averse, although this difference is far from significant $(p=0.59)$. However, when the cost is low, this difference increases sharply $(p=0.013)$, suggesting that the most ambiguity averse workers are selecting into the Safe Firm, perhaps because participants view the Risky Firm outcome as more uncertain than risky.

The right panel of Figure 4 shows the average level of Loss Aversion in each of the two firms by treatment and tells a similar story: the difference in worker Loss Aversion between the two firms widens when the workers are able to sort. Since workers in the Risky Firm face the possibility of not being paid for output that they have already worked to produce, it is very likely that this outcome would feel like a loss to them.
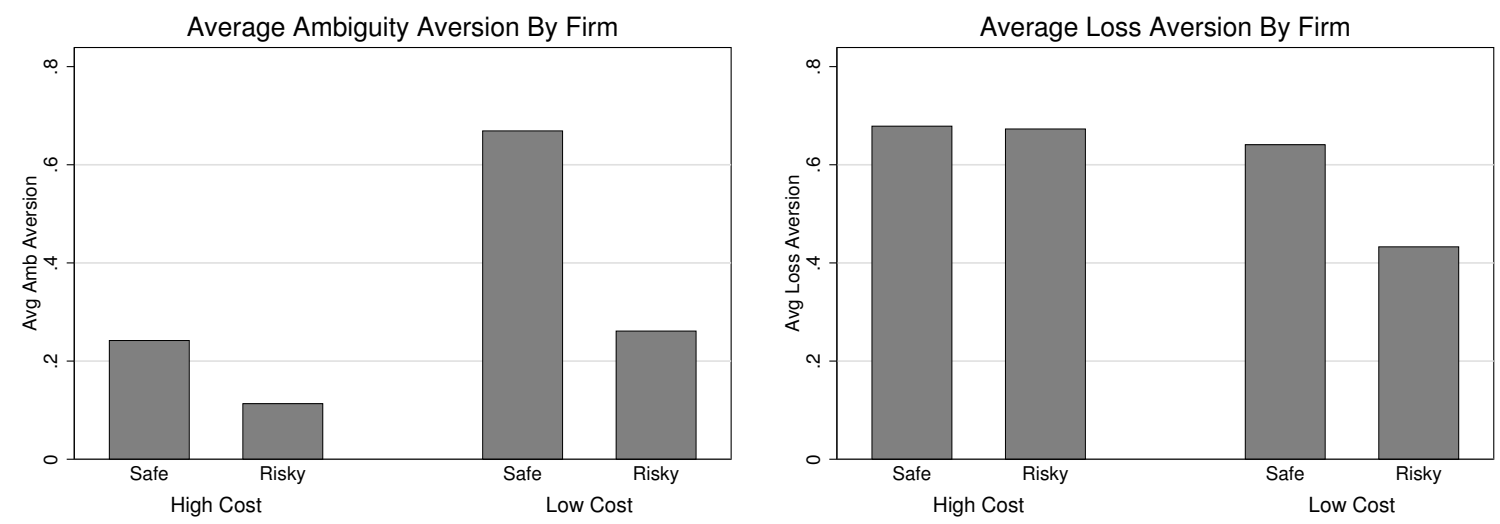

Figure 4: Ambiguity Aversion and Loss Aversion in Each Firm

The intuition from Figure 4 is confirmed by a series of probit models presented in Table 3. The dependent variable in each of these models is an indicator equal to 1 if the worker chose the Risky Firm in the period. The first two columns show that the workers respond to the piece rate differential: the higher the premium, the more likely the worker is to choose the Risky Firm. Additionally, as we would expect (and a Hausmann test confirms, $p<0.01$ ), the workers are far more responsive to the differential when the cost of commuting is low (Column 1) than when it is high (Column 2). 
Workers in the Low Cost treatment who exhibit higher levels of Ambiguity Aversion and Loss Aversion are significantly less likely to choose the Risky Firm (Column 3). This effect is not significant when costs are high (Column 4). Finally, we confirm that pure risk preferences alone do not add anything to the model (Columns 5 and 6 ), by including as an independent variable the lottery chosen in the pure Risk Choice.

We therefore conclude that workers in the Low Cost treatment are sorting into firms on the basis of their attitudes toward the disamenity, while workers in the High Cost treatment are less able to do so, suggesting that the smaller differential we see in the Low Cost treatment is indeed the result of worker selection. The differences in both behavior and differentials that we observe between our two mobility conditions supports the standard labor economics conjecture that naturally occurring differentials are likely to be lower bounds if workers can sort based on their tolerance for the disamenity.

Table 3: Sorting into Risky Firm

\begin{tabular}{|c|c|c|c|c|c|c|}
\hline & $\begin{array}{c}(1) \\
\text { Low Cost }\end{array}$ & $\begin{array}{c}(2) \\
\text { High Cost }\end{array}$ & $\begin{array}{c}(3) \\
\text { Low Cost }\end{array}$ & $\begin{array}{c}(4) \\
\text { High Cost }\end{array}$ & $\begin{array}{c}(5) \\
\text { Low Cost }\end{array}$ & $\begin{array}{c}(6) \\
\text { High Cost }\end{array}$ \\
\hline Differential & $\begin{array}{c}4.541^{* * *} \\
(0.576)\end{array}$ & $\begin{array}{c}1.270^{* * *} \\
(0.361)\end{array}$ & $\begin{array}{c}4.489^{* * *} \\
(0.589)\end{array}$ & $\begin{array}{c}1.266^{* * *} \\
(0.363)\end{array}$ & $\begin{array}{c}4.490^{* * *} \\
(0.589)\end{array}$ & $\begin{array}{c}1.209^{* * *} \\
(0.362)\end{array}$ \\
\hline Loss Aversion & & & $\begin{array}{c}-0.177^{* * *} \\
(0.052)\end{array}$ & $\begin{array}{c}-0.026 \\
(0.047)\end{array}$ & $\begin{array}{c}-0.181^{* * *} \\
(0.061)\end{array}$ & $\begin{array}{c}-0.001 \\
(0.052)\end{array}$ \\
\hline Ambiguity Aversion & & & $\begin{array}{c}-0.189^{* * *} \\
(0.053)\end{array}$ & $\begin{array}{c}-0.021 \\
(0.032)\end{array}$ & $\begin{array}{c}-0.189^{* * *} \\
(0.053)\end{array}$ & $\begin{array}{l}-0.054 \\
(0.038)\end{array}$ \\
\hline Risk Choice & & & & & $\begin{array}{l}-0.006 \\
(0.050)\end{array}$ & $\begin{array}{c}0.073 \\
(0.051)\end{array}$ \\
\hline Constant & $\begin{array}{c}-1.219^{* * *} \\
(0.114)\end{array}$ & $\begin{array}{c}-0.701^{* * *} \\
(0.098)\end{array}$ & $\begin{array}{c}-1.025^{* * *} \\
(0.122)\end{array}$ & $\begin{array}{c}-0.678^{* * *} \\
(0.100)\end{array}$ & $\begin{array}{c}-1.004^{* * *} \\
(0.215)\end{array}$ & $\begin{array}{c}-0.907^{* * *} \\
(0.194)\end{array}$ \\
\hline Observations & 420 & 480 & 420 & 480 & 420 & 480 \\
\hline
\end{tabular}

\section{Discussion}

The purpose of this study is to examine the theoretical conjecture that wage adjustments made by firms on one side of the labor market can accurately aggregate worker preferences (embodied 
in the tradeoff made between consumption and a risky disamenity) on the other. Further, we examine whether the equilibrium wage structure in this setting is affected by worker mobility and sorting, as is also hypothesized in the theory of equalizing differences. It is important to note that it is not obvious that the market will succeed in doing this: worker preferences must guide the willingness to accept job offers and firm managers must react to the signals they receive from the workers and they must also react optimally to the wage offers of other firms elsewhere on the compensation-disamenity frontier.

To the surprise of some, perhaps, we find that the process works reasonably well in the frictionless markets that characterize our experiment. Very quickly a substantial compensating differential arises and persists because risky firms must pay more to attract risk averse workers out of the "home production" sector. While the firm and preference differences combine to generate a stable differential, competition between firms is not perfect inasmuch as the compensating differential would not be enough to make a risk neutral or risk averse worker indifferent between working at the two firms, the result, we suspect, of managers maximizing some other, related, objective.

As for worker sorting, we also find strong results that support the theory. Our workers reveal risk attitudes consistent with other studies employing the same elicitation technique and they choose jobs on the basis of these preferences. Less tolerant workers sort into the safe firm and more tolerant workers find employment with the risky firm. What is interesting here is that the sorting appears to happen based on "risk-related" preferences, not baseline risk attitudes. It is worker attitudes toward ambiguity and losses that cause them to sort into the two firms. Regardless of exactly which preferences are aggregated through market dynamics, we find that sorting has a significant effect on our estimates of the differential. Because ambiguity and loss tolerant workers are willing to accept smaller premia to work at the risky firm and less tolerant workers are happy to work for lower wages at the safe firm, the equilibrium differential does shrink significantly. This suggests, as previous studies in the related literature caution, that unless sorting can be accounted for, estimates of the true average differential will be too low.

To conclude, we illustrate the potential for bias in estimates of compensating wage differentials by reorganizing our data to resemble the observational data available to (nonexperimental) researchers. Specifically, instead of the firm level data used for much of the 
Table 4: Bias due to common specification issues

\begin{tabular}{lccc}
\hline \hline & $(1)$ & $(2)$ & $(3)$ \\
& Experiment & Unobservables & Aggregation \\
\hline Risky Firm & $0.201^{* * *}$ & $0.145^{* * *}$ & \\
& $(0.014)$ & $(0.011)$ & $0.549^{* * *}$ \\
& & $(0.009)$ \\
Risky Sector & & 900 \\
\hline Observations & 854 & 854 & \\
\hline \hline & & \\
Dependent variable is log reported wage. (Robust standard errors). \\
Columns $(1)$ and $(3)$ include commuting costs, preferences and interactions. \\
In column $(2)$ preferences and costs are not included. \\
$* p<0.10,{ }^{* *} p<0.05,{ }^{* * *} p<0.01$
\end{tabular}

previous section, we look at the employee records and regress log piece rates accepted by the workers on characteristics of the job and the employee. With a sense of what the "true" differential should be, this allows us to estimate the magnitude of the bias in more conventional studies. The results are reported in Table 4. In column (1) the regression includes all the proper controls: commuting costs, worker attitudes and the interactions. In this full specification we recover the "true" differential for working in the risky firm, 20\%, also seen in columns (2)-(4) of Table 2. Here we have analyzed our experimental data "optimally" in that we have included all the proper controls for selection. In column (2) we estimate the same differential without the controls to illustrate what would happen if sorting was "unobserved." As expected, this analysis underestimates the true risky firm premium by five and a half percentage points $(p<0.01)$ because it does not account for sorting. In column $(3)$ we illustrate the potential for "aggregation bias." Imagine data was only available at the sectoral level and the risky and safe firms were lumped together in a sector because they make the same output using the same processes; however, the difference in employment risk between the two is unobserved. If this sector is compared against home production, a natural benchmark, we see that the differential can be dramatically overestimated.

\section{References}

Bonhomme, S., Jolivet, G., 2009. The pervasive absence of compensating differentials. Journal of Applied Econometrics, 24(5), 763-795. 
Carpenter, J., Cardenas, J.C., 2013. Risk attitudes and well-being in Latin America. Journal of Development Economics, 103(2), 52-61.

Dorman, P., 1998. Compensating differentials for dangerous work in a labour discipline model. Metroeconomica, 49(3), 364-385.

Dorman, P., Hagstrom, P., 1998. Wage compensation for dangerous work revisited. Industrial and Labor Relations Review, 52(1), 116-135.

Ellsberg, D., 1961. Risk, Ambiguity, and the Savage Axioms. Quarterly Journal of Economics, 75(4), 643-669.

Fehr, E., Gächter, S., Kirchsteiger, G., 1996. Reciprocal fairness and noncompensating wage differentials. Journal of Institutional and Theoretical Economics, 152(4), 608-640.

Fehr, E., Kirchsteiger, G., Riedl, A., 1996. Involuntary unemployment and non-compensating wage differentials in an experimental labour market. The Economic Journal, 106(434), 106-121.

Garen, J., 1988. Compensating wage differentials and the endogeneity of job riskiness. The Review of Economics and Statistics, 70(1), 9-16.

Goddeeris, J., 1988. Compensating differentials and self-selection: An application to lawyers. Journal of Political Economy, 96(2), 411-428.

Hamermesh, D., Wolfe, J., 1990. Compensating wage differentials and the duration of wage loss. Journal of Labor Economics, 8(1), 175-197.

Hartog, J., Vijverberg, W., 2007. On compensation for risk aversion and skewness affection in wages. Labour Economics, 14(6), 938-956.

Hey, J.D., Lee, J., 2005. Do Subjects Separate (or Are They Sophisticated)? Experimental Economics, 8(3), 233-265.

Ho, C.Y., 2013, Compensating differentials and moral hazard in the labor market. University of Rochester working paper.

Hwang, H.-s., Mortensen, D., Reed, R., 1998. Hedonic wages and labor market search. Journal of Labor Economics, 16(4), 815-847.

Hwang, H.-s., Reed, R., Hubbard, C., 1992. Compensating wage differentials and unobserved productivity. Journal of Political Economy, 100(4), 835-858.

Kniesner, T. J., Viscusi, W. K., Woock, C., Ziliak, J. P., 2012. The value of a statistical life: evidence from panel data. Review of Economic Statistics, 94(1), 74-87. 
Kostiuk, P., 1990. Compensating differentials for shift work. Journal of Political Economy, 98(5), 1054-1075.

Lavetti, K., 2014, Estimating preferences in hedonic wage models: Lessons from the Deadliest Catch. Ohio State University working paper.

Niederle, M., Segal, C., Vesterlund, L., 2013. How costly is diversity? Affirmative action in light of gender differences in competitiveness. Management Science, 59(1), 1-16.

Rao, V., Gupta, I., Lokshin, M., Jana, S., 2003. Sex workers and the cost of safe sex: the compensating differential for condom use among Calcutta prostitutes. Journal of Development Economics, 71(2), 585-603.

Rosen, S., 1986, The theory of equalizing differences. In: O. Ashenfelter, R. Layard (Eds.). Handbook of Labor Economics. Elsevier Science Publishers, Amsterdam, pp. 641-692. Smith, A. The Wealth of Nations, Chicago: University of Chicago Press, 1976 (original 1776).

Sutter, M., Weck-Hannemann, H., 2003. Taxation and the veil of ignorance - A real effort experiment on the Laffer curve. Public Choice, 115(1/2), 217-240.

Taber, C., Vejlin, R., 2011, Estimation of a Roy/search/compensating differential model of the labor market. University of Wisconsin working paper.

Viscusi, W.K., 1993. The values of risks to life and health. Journal of Economic Literature, 31(4), 1912-1946. 


\section{Appendix: Instructions}

\section{Payment and Confidentiality}

You have already earned $\$ 5$ for participating in this experiment. You may receive an additional amount of money for your participation today depending on the number of "points" you earn in the experiment. This additional amount plus the $\$ 5$ and your earnings in the first part will be paid to you in cash at the end of the experiment. The exchange rate is set so that the expected payoff from both parts is equal to $\$ 15$. The exchange rate between points and dollars is:

$$
25 \text { points }=\$ 1.00
$$

In this experiment your decisions will be confidential; none of the other participants will ever know the decisions you make.

\section{Overview}

You will be participating in this experiment with 5 other people in the room. Each participant will be assigned to a role for the duration of the experiment: 4 people will be workers and 2 will be firm managers. Each manager is associated with a firm, but workers may move between firms. The experiment will last for several periods. In each period, it will be each manager's job to set the wage rate in his/her firm. It will be each worker's job to choose a firm and then complete a task. The task involves adding together two-digit numbers and the worker's income will be based on the number of problems correctly solved and the wage rate set by the manager, as described below. At the end of the experiment, one period will be randomly selected and you will be paid your earnings from that period.

\section{Earnings}

There are two firms labeled "Red" and "Blue" and one person will be the manager of each firm for the duration of the experiment. At the start of each period, the managers will select the piece rate: the amount of points that the firm's workers will receive for each problem they are seen to correctly solve. First, one manager will choose the piece rate and the second manager will view this choice before choosing the piece rate in his/her own firm. In each period, it is randomly determined whether the Red or Blue manager chooses first.

After viewing the piece rates associated with each of the two firms, each worker will choose which firm to join for that period. (Workers are always free to select a different firm in the following period.) Rather than choosing one of the two firms, workers may also choose the "Orange" option, self-employment, which pays a piece rate of 40 points per problem solved.

After choosing whether to work for the Red or Blue Firm, or the Orange option, workers will then have one minute to work on the addition problems: adding three two-digit numbers. Finally, the workers will be paid the relevant piece rate times the number of problems they personally correctly solve as observed by the computer. We will call this number the worker's observed output and it may differ from the actual number of correctly solved problems (as explained later in the instructions). For each problem solved by a 
worker in her firm, the manager receives a payoff of 100 points minus the piece rate he/she pays. For example, let's say that there are three workers in the Red Firm and each solves 2 problems. If the manager set the piece rate at 40 , then:

Each worker earns: ( 2 problems) times (the piece rate $)=(2)$ times $(40)=80$ points

The manager earns: ( 3 workers) times ( 2 problems) times $(100-$ piece rate $)=(3)$ times $(2)$ times $(100-40)=360$ points.

\section{Difference Between Employment Options}

The two firms differ in how accurately the number of correctly solved problems is counted.

In the Red Firm and the Orange Option, the worker's observed output is always exactly equal to the number of problems the worker correctly solves.

In the Blue Firm, the worker's observed output is exactly equal to the number of problems the worker correctly solves in 3 out of 4 instances. In 1 out of 4 instances, the worker's output will not be counted and he/she will not receive any payment for that period's work. The manager of the Blue Firm is still paid for all output produced, even if the worker is not.

We can think of the firms being located in separate zones on either side of a river. Two of the four workers live in the Red Zone, near the Red Firm, and two live in the Blue Zone, near the Blue Firm. A worker who works in a firm outside of his/her zone must use the ferryboat to cross the river and, therefore, must pay a cost of 100 in each period that he/she works outside his/her zone. The workers do not have to pay the commuting cost to work in the firm within their zone. Choosing the Orange option is like working from home and also carries no commuting cost.

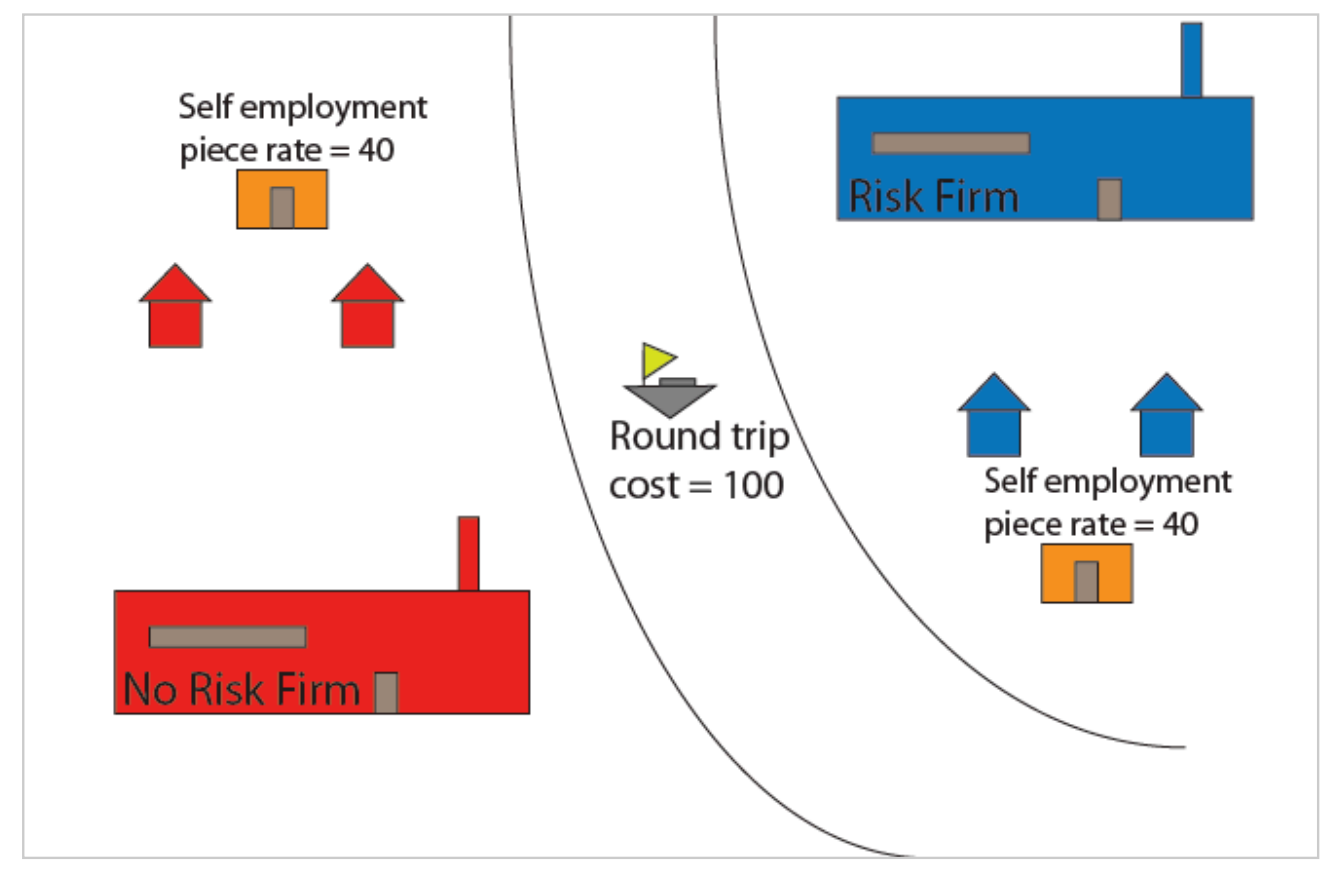


At the end of each period, each worker will learn the number of problems he/she correctly solved, the number of problems observed by the firm, the average number of problems correctly solved by all workers in all firms, his/her commuting cost, and his/her total earnings for the period.

Each manager will learn: the number of workers in his/her firm, the total output in his/her firm, the output per worker, and his/her payoff. Additionally, while choosing the piece rates, the managers will see the map above showing the results from the previous period: the piece rate in each firm, the firm choice for each of the four workers, and the payoffs of each firm manager.

\section{Summary}

In each period, each firm manager selects a piece rate. The workers view the piece rates in both firms and choose which to join. The workers then work on solving addition problems and will be paid based on how many problems they are observed to correctly solve. The observed output is determined as follows in each firm:

\begin{tabular}{|c|c|}
\hline Red Firm and Orange Option & Blue Firm \\
\hline $\begin{array}{c}\text { Observed output is equal to number of } \\
\text { problems solved. }\end{array}$ & $\begin{array}{c}3 \text { in } 4 \text { times: Observed output is equal to } \\
\text { problems solved. }\end{array}$ \\
& $\begin{array}{c}1 \text { in } 4 \text { times: Observed output is equal to } \\
\text { zero. }\end{array}$ \\
\hline
\end{tabular}

In each period, each participant receives the payoff:

\section{Manager Payoff: (100 - Piece Rate)(Total Output in Firm) Worker Payoff: (Piece Rate)(Observed Output) - Any Commuting Costs}

You will be paid in cash based on your earnings in one randomly selected period. 